\title{
2 Investigation of effects of Portland cement fineness and alkali content on 3 concrete plastic shrinkage cracking
}

\author{
4 YANG Kai ${ }^{\mathbf{a}^{*}}$ (Corresponding author), ZHONG Mingquan ${ }^{\mathrm{b}}$, MAGEE Bryan ${ }^{\mathrm{c}}$, YANG Changhui ${ }^{\mathrm{d}^{*}}$ \\ 5 (Corresponding author), WANG Chong ${ }^{\mathrm{d}}$, ZHU Xiaohong ${ }^{\mathrm{d}}$, ZHANG Zhilu ${ }^{\mathrm{d}}$ \\ 6 a: School of Civil Engineering, University of Leeds, Leeds, UK \\ 7 b: Chongqing Communications Planning Survey and Design Institute, Chongqing, China \\ 8 c: Built Environment Research Institute, Ulster University, Co. Antrim, UK \\ 9 d: College of Materials Science and Engineering, Chongqing University, Chongqing, China
}

10

\section{Abstract}

From a material viewpoint, modern concrete's frequent propensity to plastic shrinkage cracking can be attributable to a combination of low water-binder ratio use and ever-changing properties of binding materials. To obtain a better understanding of this phenomenon, this paper explores the effects of cement fineness and alkali content on the plastic shrinkage cracking of concrete manufactured with two water-binder ratios. Results indicate that within the range $275-385 \mathrm{~m}^{2} / \mathrm{kg}$, cement specific surface area is approximately directly and inversely proportional to hydration rate and evaporation rate respectively; a trend generally leading to higher plastic shrinkage and resulting areas of plastic cracking. Similar effects were observed for alkali contents which resulted in increased levels of plastic shrinkage. Furthermore, while decreasing crack tendency was noted as alkali content increased from 0.4 to $0.8 \%$ by mass of cement, further increases in alkali content caused significant decreases of compressive strength and slump; thereby lowering overall concrete performance. It is also found that plastic shrinkage cracking is closely related to the kinetics of plastic shrinkage. In summary, the experimental programme confirmed that cement with relatively low surface area (less than $340 \mathrm{~m}^{2} / \mathrm{kg}$ ) and low alkali content (less than $0.8 \%$ ) is preferred for modern concretes with minimal plastic cracking problems.

\section{Keywords:}

Shrinkage, Concrete and cement, Concrete structures, Moisture loss

$$
1 \text { page }
$$




\section{1. Introduction}

2 Plastic shrinkage refers to shrinkage of concrete occurring in the first 24 hours after batching, caused 3 by external drying and cement hydration effects $[1,2]$. These cracks do not only affect aesthetics of structures, but also permit transport of moisture and other aggressive species. As a result, concrete strength and durability performance can be compromised [3, 4]. Reflecting its seriousness, the topic of plastic shrinkage and cracking has been the focus of concrete researchers and engineers for decades [5-7].

8 Despite best efforts to avoid the problem [2,6,7], plastic shrinkage cracking is still very common in regions where the weather is hot and dry. This is particularly true for modern concretes which appear more sensitive to cracking immediately after setting [8]. From a material point of view, the main factors attributing to this trend include changes in binder material properties, high binder contents, low water/cement ratio $(\mathrm{W} / \mathrm{C})$ and admixture use and variability $[9,10]$. As such, high cracking frequencies cannot be considered as completely unexpected. While considerable literature exists covering different parameter effects on plastic shrinkage and plastic cracking $[2,9,11,12]$, the influence of cement properties is still relatively unexplored. Clearly this knowledge would provide construction professionals with a relatively straightforward material specification approach to reducing risks associated with plastic cracking.

This guidance would, for example, be particularly welcomed by construction professionals in China. After 20 years of development focussed along its eastern seaboard, considerable infrastructure construction is now underway in the south west of China.

A general concern for the construction industry in this area is plastic cracking due to the demanding environment conditions in this region where temperatures at concrete surfaces in the summer can easily reach $60{ }^{\circ} \mathrm{C}$ with wind speeds varying from $5-10 \mathrm{~m} / \mathrm{s}$. Furthermore, while properties of local cements have undergone several changes in recent years, few published reports outlining these changes, not to mention their effects on plastic shrinkage cracking, are available.

Conscious of these problems, a western traffic science and technology project was funded in 2009 to survey properties of cement throughout the southwest part of China and investigate their effects on plastic cracking [13]. Chemical and physical properties of cements from 233 manufacturers were examined and the primary results are given Figure 1. It can be seen from Figure 1 that around $86 \%$ of cements have a specific area varying from $320-360 \mathrm{~m}^{2} / \mathrm{kg}$, with $9 \%$ having an even higher specific area $\left(>360 \mathrm{~m}^{2} / \mathrm{kg}\right)$. The other trend noted is high cement alkali content, with $95 \%$ samples having values higher than $0.6 \%$ by mass. These trends in cement production are similar to those experienced in Western counties, where finer materials were introduced to deliver perceived performance benefits 
1 such as increased strengths, reduced cement contents for a given specific strength, earlier removal of

2 formwork, and faster construction times [14-16]. Unfortunately, such benefits are also associated with

3 potential disadvantages such as an increased risk of plastic shrinkage cracking.

4 This paper addresses the effect of Portland cement quality, namely in terms of fineness of cement 5 particles and alkali content, on plastic shrinkage cracking. A comprehensive experimental programme 6 is reported with results for hydration rate, evaporation, plastic shrinkage, crack width and cracking 7 area presented. These results are intended to provide engineers and contractors with an insight into the 8 fundamental behaviour of plastic cracking and assistance in selecting proper approaches to its 9 avoidance.

\section{Experimental programme}

\subsection{Experimental variables investigated}

Based on data obtained from the aforementioned survey of cement [13] and relevant literature [1719], the three main parameters considered in this study were cement fineness, cement alkali content and water-cement ratio $(\mathrm{W} / \mathrm{C})$. As summarised in Table 1, ranges considered for these properties were $275-385 \mathrm{~m}^{2} / \mathrm{kg}, 0.4-1.2 \%$ by mass and $0.35-0.40$ respectively.

To prepare cements with different fineness and alkali contents, pure clinker manufactured from Lafarge, as characterised chemically in Table 2, was used. The clinker was ground for different periods in a ball mill to yield the required fineness levels of 275,337 and $385 \mathrm{~m}^{2} / \mathrm{kg}$. In each case, gypsum was added at a rate of $5 \%$ by mass.

Alkali contents were adjusted by adding $\mathrm{NaOH}$ (chemical pure) into water during the concrete mixing stage to ensure equivalent cement alkali contents of $0.4,0.8$ and $1.2 \%$ by mass.

The effect of W/C (0.35 and 0.4$)$ on shrinkage-induced cracking was also investigated, mainly because low W/C is a key feature of modern concretes generally leading to increased autogenous shrinkage and early age cracking sensitivity $[12,20]$.

As plastic shrinkage cracking relies heavily on numerous parameters, including: water evaporation rate; settlement and capillary pressure; hydration kinetics; concrete materials and mix proportions; and environmental conditions (e.g. temperature, relative humidity and wind speed) [5, 11, 18], assessment of its risk is not straightforward and not easily determined by considering only selective properties [21-23]. 
1 Therefore, a comprehensive range of assessment techniques was employed to consider general concrete properties (slump and compressive strength), influencing properties (cement hydration, water evaporation rate, plastic shrinkage levels) and response properties (maximum cracking width, cracking area). This testing programme is also summarised in Table 1.

\subsection{Concrete mixes}

Table 3 shows the quantities of the constituent materials used in each of the concrete mixes investigated. Ten concretes were tested in total resulting from the two $\mathrm{W} / \mathrm{C}$ ratios $(0.35$ and 0.4$)$, three levels of cement fineness $\left(275,337\right.$ and $\left.385 \mathrm{~m}^{2} / \mathrm{kg}\right)$ and three levels of cement alkali content $(0.4,0.8$ and $1.2 \%$ by mass) considered. The approach used was to hold the cement content constant at 420 $\mathrm{kg} / \mathrm{m}^{3}$ and adjust the water content to achieve the require W/C. In terms of workability, all concrete mixes were designed for a slump range of $160 \pm 20 \mathrm{~mm}$. To obtain this, suitable dosages of a polycarboxylic acid-based polymer superplasticiser (SP) were used. The fine aggregate (FA) was medium graded natural sand and the coarse aggregate (CA) crushed limestone comprising both 10 and $20 \mathrm{~mm}$ sized materials proportioned in a ratio of 3:7. The water used in the study was from the mains supply in Chongqing.

Concrete was prepared using a pan mixer with a capacity of $0.035 \mathrm{~m}^{3}$ and tested for slump immediately after mixing according to GB/T 50080 [24]. From Table 3, it can be seen that all concretes achieved, or closely achieved, the target slump range. The main exception was the concrete prepared with $0.35 \mathrm{~W} / \mathrm{C}$ and cement alkali content of $1.2 \%$ by mass. In this instance, the low slump achieved $(98 \mathrm{~mm})$ was most likely due to the superplasticiser's inability to function properly at such a high alkali condition.

\subsection{Test methods}

\subsubsection{Calorimetry}

The process of cement hydration was measured by an isothermal calorimeter (TAM Air-8 channel) sensitive to $\pm 20 \mu \mathrm{W}$. Five minutes after mixing, cement paste samples with a water:cement ratio of 0.4 were placed into the calorimeter and the first environment-calibrated reading captured 10 minutes later. All subsequent measurements were carried out at an ambient temperature of $20{ }^{\circ} \mathrm{C}$ with a time resolution of $1 \mathrm{~min}$. While it is recognized that cement paste samples do not fully represent concrete hydration rates, the calorimetry results were used to provide an indication of the effect of cement fineness and alkali content on the kinetics of hydration. 
2 Immediately after casting, plastic shrinkage was assessed using the non-contact method specified in

3 GB/T 50082 [25]. As illustrated in Figure 2, a non-contact laser transducer was used to measure 4 linear movement in $100 \times 100 \times 500 \mathrm{~mm}^{3}$ concrete specimens via reflecting plastic probes placed in the 5 end face of each specimen. To limit friction and seal joints, the inner walls of specimen moulds were coated with Teflon tapes and mould surfaces covered with two layers of plastic sheet.

7 Moulds were filled with concrete in two layers and compacted on a vibrating table until no air 8 appeared at the surface. Immediately after casting, specimens were subjected to high evaporation rates 9 in a wind tunnel under controlled extreme environment conditions $\left(20 \pm 2{ }^{\circ} \mathrm{C}, 60 \pm 5 \%\right.$ relative humidity (RH), and wind speed $8 \pm 2 \mathrm{~m} / \mathrm{s}$ ).

Plastic shrinkage measurements were recorded and logged on a computer every 10 minutes for 24 hours.

\subsubsection{Plastic cracking}

Plastic shrinkage induced cracking was measured by a method developed by Chongqing University and similar to that prescribed in ASTM-C1579 [26]. As shown in Figure 3, $380 \times 600 \times 70 \mathrm{~mm}^{3}$ concrete slabs were cast in moulds comprising a profiled base providing two outer horizontal restraints and a central crack-inducer.

After casting and compaction, the test moulds were exposed to the extreme environmental exposure described above for plastic shrinkage assessment (temperature: $20 \pm 2{ }^{\circ} \mathrm{C}$; $\mathrm{RH}$ : $60 \pm 5 \%$; wind speed: $8 \pm 2 \mathrm{~m} / \mathrm{s})$.

Crack initiation was determined visually by inspecting specimen surfaces every 30 minutes. After 6 hours, maximum and mean cracking widths were visually measured using a microscope (100x magnification). The length and average width of cracks was recorded and expressed as total cracked area. Two moulds were prepared for each concrete mix and the average value reported.

\subsubsection{Rate of water evaporation}

In parallel with studies of plastic shrinkage and plastic shrinkage cracking, evaporation rates were determined for all mixtures using cylindrical water samples $(\Phi 200 \mathrm{~mm} \times 30 \mathrm{~mm})$. Specimens were subjected to the same exposure conditions used for measuring plastic shrinkage cracking (temperature: $20 \pm 2{ }^{\circ} \mathrm{C}$; RH: $60 \pm 5 \%$; wind speed: $8 \pm 2 \mathrm{~m} / \mathrm{s}$ ) and weighed to a precision of $0.01 \mathrm{~g}$. The rate of water evaporation was determined by dividing the mass loss by the surface of the cylinder. 


\section{3. Results and discussion}

3.1 Effect of cement fineness and alkali content on cement hydration and compressive strength

Provided in Figure 4 are established relationships between cement fineness and hydration. Clearly from Figure 4-a, total heat of cement hydration is positively related to the specific area of cement particles, with evolved heat increasing from 219 to $253 \mathrm{~J} / \mathrm{g}$ as the specific area of cement increased from 275 to $385 \mathrm{~m}^{2} / \mathrm{kg}$. As a result, and illustrated in Figure 4-b, this led to higher rates of total heat release, with a value range of $2.5-3.9 \mathrm{~mW} / \mathrm{g}$ corresponding to cement specific areas of $275-385 \mathrm{~m}^{2} / \mathrm{kg}$. Also clear from Figure 4-b is that the significant effect of particle size on cement hydration was apparent for the first 12 hours only. Thereafter, paste hydration rates were nearly equivalent. The trends noted in Figure 4 are, perhaps, not surprising as it is recognised that higher specific area aids the dispersion of cement and speeds reactions during early hours; particular for periods where hydration is controlled by nucleation and growth [27, 28]. Important for this study, rapid hydration is predicted to cause several changes in concrete properties, including less bleeding, loss of workability, and faster development of shrinkage, strength and elastic modulus. As a result, coarser cement is potentially preferable for making modern concrete.

Relationships between alkali content and cement hydration are shown in Figure 5. Similar to effects of cement fineness, it can be seen that increasing alkali content generally accelerated cement hydration. However, while increases in both heat and rate of hydration were noted as alkali contents increased from 0.4 to $0.8 \%$ by mass of cement, this relationship was not positive as the alkali content increased to $1.2 \%$ by mass. This finding suggests that hydration is not a simple function of alkali content, which is justifiable given that alkali is known to affect both physical and chemical conditions of hydration $[14,29]$.

With compressive strength being a key concrete property reflecting processes of both hydration and micro-structure development, impacts of cement fineness and alkali content on this parameter are shown in Figure 6.

As shown in Figure 6-a, relationships between concrete compressive strength and cement fineness are similar to the calorimetry-based trends plotted in Figure 4, with increasing cement fineness correlating to improved concrete strength. For 0.35 water:cement ratio concrete, for example, 28-day strengths increased from 61-74 MPa as cement fineness increased from 275-385 $\mathrm{m}^{2} / \mathrm{kg}$. With respect to effects of alkali content the opposite trend was observed, with compressive strength generally decreasing with increasing alkali content. For 0.35 water:cement ratio concrete, for example, 28-day strengths decreased from $68-49 \mathrm{MPa}$ as alkali contents increased from $0.4-1.2 \%$ by mass of cement. 
1 This trend may be attributed to the formation of less favourable microstructures caused by

2 modifications to the morphology of C-S-H and calcium hydroxide phases [15, 27].

3 Also clear from Figure 6 is that the influences of cement fineness and alkali content described above

4 were more pronounced at the lower $\mathrm{W} / \mathrm{C}$ ratio concrete, suggesting that modern concretes may be

5 more sensitive to changes in cement properties.

\section{$6 \quad 3.2$ Effect of cement fineness and alkali content on plastic shrinkage of concrete}

7 Illustrated in Figure 7 are influences of W/C ratio and cement fineness on the plastic shrinkage of the

8 six concretes examined in this study. Over the 24-hour test period, plastic shrinkage trends may be

9 summarised in the following distinct stages.

In the initial 7 hours, plastic shrinkage of all concretes evolved linearly with time, with rates clearly dependent on cement fineness. Corresponding 7-hour shrinkage values for concrete made with cement fineness 275,337 and $385 \mathrm{~m}^{2} / \mathrm{kg}$ were 490,900 and $1500 \mu \mathrm{m} / \mathrm{m}$ respectively. Conversely, little or no impact of $\mathrm{W} / \mathrm{C}$ ratio was noted during this period. While rates of plastic shrinkage significantly decreased from 7-12 hours, a clear impact of W/C ratio emerged in this period, with lower W/C ratio concrete exhibiting higher shrinkage at each cement fineness level. For concretes using cement with a fineness of $337 \mathrm{~m}^{2} / \mathrm{kg}$, for example, 12-hour shrinkage values for the 0.35 and $0.40 \mathrm{~W} / \mathrm{C}$ concretes were 2,000 and $1,400 \mu \mathrm{m} / \mathrm{m}$ respectively. Beyond this period, plastic shrinkage increased marginally until constant values were reached at approximately 18 hours.

Within the initial 0-7 hour period, plastic shrinkage is known to involve both autogenous and drying shrinkage $[2,6,20,23]$, with the former mainly caused by chemical shrinkage as self-desiccation effects may not have started yet $[4,28]$. Equally, it is reported that higher values of cement fineness generally lead to accelerating hydration rates of the clinker particles [30] (evidenced in this study by Figure 4), resulting in higher chemical shrinkage levels at early ages.

In terms of drying shrinkage effects, increasing cement fineness and decreasing W/C may have resulted in increased levels of induced capillary tension. An explanation for this may be that finer cement and lower $\mathrm{W} / \mathrm{C}$ results in denser concrete pore structures, thereby raising capillary tension levels. Indeed, according to the Laplace's equation [18, 31, 32] capillary depression is inversely proportional to pore diameter. Effects of cement fineness and W/C ratio on concrete bleeding and surface water evaporation rates may also further justify differences in capillary tension levels. It is proposed, therefore, that the use of fine cement and lower W/C concrete will lead to reduced bleeding rates and increased capillary tension levels, even at relatively low surface water evaporation rates. 
1 The effect of cement fineness and W/C on surface water evaporation rate is illustrated in Figure 8. As expected, increasing specific area of cement and decreasing W/C led to a decrease in the amount of water evaporation. While previous work $[12,33]$ has indicated a direct correlation between plastic shrinkage levels and evaporation rates, other factors such as bleeding amount, W/C ratio and environmental conditions are also important. This is because capillary tension is formed and drying shrinkage develops, once water evaporation exceeds bleeding rates.

To assess the effect of alkali content, Figure 9 presents relationships between plastic shrinkage and time for concrete with a $\mathrm{W} / \mathrm{C}$ ratio of 0.35 and 0.40 and alkali contents varying from 0.4 to $1.2 \%$ by mass of cement. As was the case for effects of cement fineness in Figure 7, the results in Figure 9 may be summarised in several distinct stages over the 24-hour test period, including: rapidly and gradually increasing shrinkage from 0-7 and 7-12 hours respectively, followed by minimal increases thereafter.

Unlike the influence of cement fineness, however, complex interactions between alkali content, W/C ratio and plastic shrinkage were noted in Figure 9. For the $0.40 \mathrm{~W} / \mathrm{C}$ ratio concrete, for example, concretes with alkali content 0.4 and $1.2 \%$ yielded similar ultimate shrinkage levels $(1,300 \mu \mathrm{m} / \mathrm{m})$ after 24 hours, compared to a higher value $(1,500 \mu \mathrm{m} / \mathrm{m})$ for the $1.2 \%$ alkali content concrete. With higher shrinkage levels measured for the $0.35 \mathrm{~W} / \mathrm{C}$ ratio concretes, ultimate values of $1,700,2,500$ and $1,800 \mu \mathrm{m} / \mathrm{m}$ were measured for the $0.4,0.8$ and $1.2 \%$ alkali content concretes after 24 hours.

In general, increasing shrinkage with alkali content was expected due to chemical shrinkage affects, as addition of alkali introduced more $\mathrm{OH}^{-}$in the matrix; thereby accelerating cementitious reactions, and in particular those associated with $\mathrm{C}_{3} \mathrm{~A}$ and $\mathrm{C}_{3} \mathrm{~S}$ [27, 34]. This potential effect is particularly significant for the first 10 hours as shown in Figure 4. The non-linear trends noted in Figure 9 are considered to correspond to induced variations of bleeding, evaporation and surface tension of pore solution caused by increases in alkali contents.

Relationships between evaporation rate and alkali content are given Figure 10, which clearly shows decreasing rates with increasing alkali content, particularly for the $0.40 \mathrm{~W} / \mathrm{C}$ concrete. Evaporation rates plotted in Figure 10 are lower than that shown in Figure 8, especially for concretes with a W/C ratio of 0.4 . This corresponds to the fact that initial ion concentration is relatively low and additional alkali can raise the concentration significantly. As sodium hydroxide accelerated cement hydration, the time for concrete to maintain its plasticity was shortened, quickly forming a solid skeleton which made it difficult for bleeding water to move to the surface. Meanwhile, it is known that addition of alkali can reduce vapour pressure according to Raoult's law [35]. In other words, it becomes more difficulty to remove bleeding water from the surface. Clearly a combination of lower levels of bleeding water and vapour pressure would result in less surface evaporation occurring. 
1 Despite lower evaporation rates, this does not necessarily imply lower plastic shrinkage values. As 2 dictated by fundamental thermodynamic theory [35], the surface tension of liquids is directly related to its concentration of soluble inorganic salt. In this study, sodium hydroxide was added in the system and, as a result, surface tension is believed to increase with increasing alkali contents. Furthermore, less bleeding water on the surface of concrete accelerates build-up of capillary pressure. Assuming all other variables to be constant, therefore, any increase in alkali content should lead to greater surface tension due to formation of a finer concrete pore structure leading to greater capillary pressures. Therefore, plastic shrinkage increases with alkali content due to its induced chemical and drying shrinkage.

Note that compressive strength and slump results for concrete with $1.2 \%$ by mass alkali content (shown in Table 3 and Figure 6) exhibited abnormal trends, suggesting that high alkali content not only cause high shrinkage but also raises other practical issues.

An interesting aspect to be noted from Figure $\mathbf{7}$ and $\mathbf{9}$ is that the effect of W/C only became significant from 7 to 10 hours. As indicated from the calorimetry data (Figures 4 and 5), only very small differences in hydration reactions were noted after 12 hours despite the different cement fineness and alkali contents. It may be deduced that this effect is mainly caused by drying, rather than chemical shrinkage. This means that shrinkage in the first 7 hours was mainly controlled by the properties of cement. Beyond this time, a solid skeleton was developed and the extra water taken up early due to osmotic effects (plus bleeding water, if present) combined with water driven through the membrane by relative humidity and pressure gradients. Accelerated hydration yielded a finer pore structure making moisture transport more difficult. Use of a low W/C (corresponding to low water content) means lack of bleed water to replace evaporating water. As a result, plastic shrinkage of concrete with low $\mathrm{W} / \mathrm{C}$ and faster hydration rate achieves the highest value. This confirms recommendations of Aictin and Neville [36], who concluded that, under constant testing conditions, high performance concrete tends to have greater shrinkage at early stages than normal concrete.

\section{3 Effect of fineness of cement and alkali content on plastic cracking of concrete}

Maximum crack width is recognised as a common parameter describing plastic cracking behaviour, which should be carefully controlled for the safety of concrete structures. Figure 11-a plots measured values in relation to cement fineness and $\mathrm{W} / \mathrm{C}$ ratio. Clearly from this figure, $\mathrm{W} / \mathrm{C}$ ratio had a significant influence on crack width, with higher values noted for 0.40 , in comparison to $0.35 \mathrm{~W} / \mathrm{C}$ concretes considered. Also evident is a trend of decreasing crack width with increasing specific area of cement. This was especially pronounced for the $0.40 \mathrm{~W} / \mathrm{C}$ concrete, with crack widths decreasing by around $50 \%$ (from 2.1 to $1.2 \mathrm{~mm}$ ) as cement specific area increased from 275 to $385 \mathrm{~m}^{2} / \mathrm{kg}$. For the $0.35 \mathrm{~W} / \mathrm{C}$ concrete, this decrease was lower at around $20 \%$, with crack widths reducing from 1.1 
1 to $0.8 \mathrm{~mm}$ as cement specific area increased from 275 to $385 \mathrm{~m}^{2} / \mathrm{kg}$. These trends are expected and 2 attributable to increased particle settlement and lower tensile strength associated with concretes with 3 higher W/C and coarser cement. Finer cement speeds up hydration processes resulting in higher 4 tensile strength and improved cracking-resistance. This impact is especially significant for high W/C concrete, as slow rates of tensile strength development mean that relative small restrained shrinkage can be high enough to cause cracking [7, 21, 37].

7 As plastic cracking of concrete is a complicated phenomenon not fully explained by maximum 8 cracking width data alone, the influence of cement fineness on total cracking area was also examined as shown in Figure 11-b.

It is recognised that cracks less than $0.3 \mathrm{~mm}$ wide are considered not to directly influence the safety of concrete structures, so are typically ignored by structural designers. However, these cracks have a significant impact on durability, as detrimental ions or matter can transport more rapidly into concrete. Given also that total cracking area is always associated to the materials (concrete, mortar or paste) in question, this parameter was also considered in this study. Similar to the results in Figure 11-a, W/C ratio had a clear effect, with $0.4 \mathrm{~W} / \mathrm{C}$ concrete generally yielding significantly greater cracking areas than $0.35 \mathrm{~W} / \mathrm{C}$ concrete. In this case, however, increasing specific area of cement particles resulted in corresponding increases in total areas of cracking. Furthermore, concrete with the lower W/C of 0.35 appeared more sensitive to cement fineness, with a $20 \%$ increase (from 320 to 390 $\mathrm{mm}^{2}$ ) in cracked area noted. The corresponding increase for $0.4 \mathrm{~W} / \mathrm{C}$ concrete was around $5 \%$ (from 590 to $620 \mathrm{~mm}^{2}$ ). This trend appears to be somewhat contrary to results in Figure 11-a, indicating the complicated nature of plastic cracking.

Combining the results in Figures 11-a and $\mathbf{b}$, it may be deduced that plastic cracks become longer and finer when cement with a higher specific surface is used. In other words, the intensity of plastic cracking increases with decreasing size of cement particles and this feature is more significant for concrete with lower W/C. As the tensile strength of concrete with higher W/C and coarser cement develops more slowly, cracking may occur earlier and, after this, stress is relieved. At the same time, resultant stresses start to redistribute, leading to increasing crack width and depth [32]. Therefore, cracks tend to take place at earlier stages for concrete with a higher $\mathrm{W} / \mathrm{C}$ and coarser cement, which naturally leads to wider but fewer cracks.

Figure 12 plots the relationship between both maximum crack width and total area of cracking versus cement alkali content. It can be seen from Figure 12-a that concrete with higher W/C generally exhibited greater crack widths, albeit that this trend diminished with increasing cement alkali content. This is because cement alkali content had a limited effect on maximum crack width for the $0.40 \mathrm{~W} / \mathrm{C}$ concrete, whereas crack widths increased rapidly with increasing cement alkali content for the 0.35 
$1 \mathrm{~W} / \mathrm{C}$ concrete. Indeed, it can be seen from Figure 12-a that at a cement alkali content of $1.2 \%$ by mass, the maximum crack width of the $0.35 \mathrm{~W} / \mathrm{C}$ concrete $(1.75 \mathrm{~mm})$ exceeded that of the $0.40 \mathrm{~W} / \mathrm{C}$ concrete $(1.5 \mathrm{~mm})$.

4 It can be seen from Figure 12-b, which plots total cracked area as a function of cement alkali content, that total cracked area dramatically decreased as cement alkali content increased from 0.4 to $0.8 \%$ by mass of cement. This decrease was particularly marked for the $0.40 \mathrm{~W} / \mathrm{C}$ ratio concrete, with cracked areas decreasing from 620 to $400 \mathrm{~mm}^{2}$. For the $0.35 \mathrm{~W} / \mathrm{C}$ concrete, corresponding values of cracked area were 350 and $300 \mathrm{~mm}^{2}$. As alkali content increased to $1.2 \%$ by mass, further decrease in cracked area for the $0.40 \mathrm{~W} / \mathrm{C}$ ratio concrete were minimal, while for the $0.35 \mathrm{~W} / \mathrm{C}$ ratio concrete values increased to $400 \mathrm{~mm}^{2}$. This trend suggests that suitable amounts of alkali can reduce plastic cracking, but the opposite may occur if the alkali content is too high. This finding may be explained by the fact that alkali content not only affect rates of hydration acceleration, but also surface tension, bleeding and evaporation processes $[27,28]$. As a result, no simple relationship can be established between cement alkali content and cracking behaviour.

As one principal cause of plastic shrinkage cracking is evaporation of water, various recommendations, for example ACI 305 [38], have been proposed to assess associated risks. Figure 13 plots relationships between evaporation rate at 5 hours and both maximum cracking width and total area of cracking. As expected, both cracking-related parameters generally rise continuously with increasing evaporation rate, but these relationships are broad and do not follow a simple function.

This suggests that moisture loss at early ages is a main driving force for plastic cracking occurrence, but that considering this parameter alone may not be sufficient to more accurately predict cracking performance. In addition, all evaporation rates plotted in Figure $\mathbf{1 3}$ are less than the 'high-risk' evaporation rate of $1.0 \mathrm{~kg} / \mathrm{m}^{2} \mathrm{~h}$ specified in ACI 305 [38]. This observation is perhaps not surprising, given the approach employed in the current study. Firstly, rates of evaporation clearly rely on bleeding associated with specific concretes. As indicated in previous sections, the concretes tested in this study had relatively low W/C, resulting in corresponding low bleeding rates. Secondly, drying at early ages is a very complex process, involving various chemical and physical processes $[4,15,38]$. As such, properties of concrete can no longer be considered constant and simplified calculations cannot be used to make predictions. Accurate predictions of cracking, therefore, cannot be successfully performed based on magnitudes of water evaporation alone. This agrees with work by Bjøntegaard et al. [10] and Kwak and Ha [21] who have pointed out similar issues associated with assessing risks of plastic cracking using evaporation rates.

Against this background, careful consideration of several parameters is required to better understand effects of cement fineness and alkali content on plastic cracking. Internal concrete properties and 
external actions of significance include tensile strength, elastic modulus (E-modulus), creep, restraint conditions and shrinkage at early ages $[11,17,37]$. If shrinkage of concrete is restrained, tensile stresses generated lead to cracking when the tensile strength of concrete is exceeded. As cement hydration progresses, increasing tensile strength is beneficial in terms of avoiding cracking risk while increasing E-modulus is potentially detrimental as a given restrained deformation will produce a higher stress [6,33]. Furthermore, to estimate plastic shrinkage-induced stress, values of net shrinkage (equal to total shrinkage minuses creep) and effect of restrict conditions are required. Although the restraint condition is a constant in this study owning to the test set-up used, it is difficult and expensive to obtain values of creep relaxation for early age concrete $[18,21]$. An alternative approach is to consider total values and kinetic characteristics of shrinkage to assess risks of plastic cracking, as they are directly related to the magnitude of creep and shrinkage-induced stress [28, 32].

For concrete with a W/C of 0.40 only, Figure 14 plots shrinkage values and derived growth rates of shrinkage against time up to a period of six hours after mixing. These properties are plotted to investigate the influence of both cement fineness (Figures 14-a and -b) and alkali content (Figures 14-c and -d). From Figure 14-a, concrete made with finer cement (385 versus $275 \mathrm{~m}^{2} / \mathrm{kg}$ ) exhibited significantly larger shrinkage after six hours $(1,200$ versus $450 \mu \mathrm{m} / \mathrm{m})$. Figure 14-b confirms corresponding higher rates of shrinkage development with time for the finer cement concrete, with peak rates occurring around four hours after mixing. Peak shrinkage rates for the 385 and $275 \mathrm{~m}^{2} / \mathrm{kg}$ cement fineness concrete were 200 and $85 \mu \mathrm{m} / \mathrm{m}$.h respectively. These trends indicate that relaxation due to creep becomes lower, yielding higher induced stresses. Consequently, it is reasonable to predict higher cracking areas for concrete made with finer cements.

Compared with Figure 14-a, similar trends for the effect of cement alkali content are clear from Figure 14-c, with higher alkali content ( 0.8 versus $0.4 \%$ by mass) resulting in larger shrinkage after six hours $(1,150$ versus $740 \mu \mathrm{m} / \mathrm{m})$. A feature to note from Figure 14-d is the effect of alkali content on the rate of shrinkage growth within the first few hours of hydration. Clearly the concrete containing low alkali cement ( $0.4 \%$ by mass) exhibited significantly greater growth rates within first 2-3 hours. This may be associated with both lower evaporation rates due to increased surface tension and acceleration of hydration. This implies that stress relaxation increases with alkali content up to 23 hours after mixing, giving a reduced cracking risk. After 2-3 hours, corresponding to the time of initial setting, the network of the solid particles becomes progressively stiffer, leading to higher tensile strength and ability to resist cracking. Consequently, it may be concluded that total cracking areas are likely to decrease with increasing cement alkali content.

Special attention should be given to effects of alkali content, however, as decreased cracking tendency may not always be seen, especially for concrete with low W/C ratio. Furthermore, high alkali contents 
may also contribute to longer term concrete durability problems [39, 40] and incompatibility with admixtures such as superplasticisers $[27,28]$.

\section{Conclusions}

4 In the southwest of China, Portland cement properties are highly variable, with fineness values 5 generally in the range $320-360 \mathrm{~m}^{2} / \mathrm{kg}$ and alkali contents typically below $0.9 \%$ by mass of cement. 6 Experimental results from the comprehensive research study reported indicate that both cement 7 fineness and alkali content have a significant influence on hydration kinetics, bleeding, evaporation, 8 plastic shrinkage and plastic shrinkage cracking of cement-based materials. Based on the data reported, the following main conclusions can be drawn:

1. Increasing cement fineness results in increased hydration and decreased evaporation rates for a given $\mathrm{W} / \mathrm{C}$ and constant cement hydration environment. As such, both plastic shrinkage and compressive strength of concrete increase with increasing cement fineness. Concrete made using coarser cement is likely to exhibit slightly higher cracking widths, but reduced intensity of plastic cracking in comparison to finer cement concretes. Although no up limit of cement fineness is specified in the Chinese national standard (Common Portland cement: GB-175), Portland cement fineness should ideally be limited at around $350 \mathrm{~kg} / \mathrm{m}^{2}$ to prevent plastic cracking. This limit will also have positive energy and greenhouse gas impacts due to reduced grinding times.

2. While increasing cement alkali content accelerates cement hydration and decreases water evaporation rates, other key concrete properties are not improved. For example, slump, plastic shrinkage and compressive strength values of concrete are all impacted upon negatively as cement alkali content increases above $0.8 \%$ by mass. With respect to plastic shrinkage cracking, an appropriate level of alkali content (less than $0.8 \%$ by mass) is beneficial for reducing cracking widths and areas, especially for concrete with high $\mathrm{W} / \mathrm{C}$ ratios.

3. Results of testing undertaken to assess water evaporation rates alone are not reliable and sufficient to assess risks of concrete plastic cracking. This is because plastic shrinkage cracking is a complex phenomenon involving various interdependent influencing factors, including tensile strength, creep, E-modulus, restraint conditions and shrinkage characteristics.

4. To enable predictions of plastic cracking risk, it is critical to appreciate overall characteristics of shrinkage at different stages (total shrinkage and shrinkage kinetics) which are helpful to control potential cracking. Results indicate that concrete with a high shrinkage rate in the first 2-3 hours after mixing is prone to higher cracking areas. Beyond this time, concrete develops sufficient strength to resist plastic cracking. For construction professionals, this emphasises the fact that any approach adopted to avoid extensive surface water evaporation should be applied as soon as possible. 


\section{Industry recommendations}

1. Cement manufacturers need to control material properties including fineness and alkali content carefully, as they influence plastic shrinkage and cracking of concrete significantly.

2. For major projects, engineers/contractors need to specify concrete with limits imposed on cement fineness (less than $350 \mathrm{~m}^{2} / \mathrm{kg}$ ) and alkali content (less than $0.8 \%$ by mass of cement). Furthermore, the use of internal curing, shrinkage reducing admixtures and paraffin should be considered to reduce plastic shrinkage risks in critical projects.

3. Effective curing according to Chinese code for construction of concrete structures (GB506662011) needs to be applied on site to limit surface water evaporation and risk of plastic cracking.

4. Addition of suitable amounts of supplementary cementitious materials and/or fibres should be considered to improve plastic cracking resistance. Moreover, essential cracking experiments should be undertaken when using chemical or mineral admixtures in concrete.

\section{Acknowledgement}

This work was funded by the western traffic science and technology project (NO. 2009-318-000 033), National Science Foundation of China (NO. 51408078), the open fund from Shenzhen University and Chongqing Jiaotong University (NO. LHSYS-2016-008). The supports from Ulster University and University of Leeds during this project are also gratefully acknowledged.

\section{References}

1. Cortas R, Rozière E, Staquet S, Hamami A, Loukili A, Delplancke-Ogletree M P. Effect of the water saturation of aggregates on the shrinkage induced cracking risk of concrete at early age. Cement and Concrete Composites, 2014. 50: 1-9.

2. Leemann A, Nygaard P, Lura P. Impact of admixtures on the plastic shrinkage cracking of selfcompacting concrete. Cement and Concrete Composites, 2014. 46: 1-7.

3. Neville AM. Maintenance and durability of structures. Concrete International, 1997. 19: 52-56.

4. Aitcin PC. High performance concrete. 1998: Spon Press.

5. William L. Plastic shrinkage. ACI Journal, 1957. 53: 797-802.

6. Aly T, Sanjayan JG. Factors contributing to early age shrinkage cracking of slag concretes subjected to 7-days moist curing. Materials and Structures, 2007. 41(4): 633-642.

7. Sule M, van Breugel K. The effect of reinforcement on early-age cracking due to autogenous shrinkage and thermal effects. Cement and Concrete Composites, 2004. 26(5): 581-587. 
8. Neville AM, Aitcin PC. High performance concrete- An overview. Materials and Structures, 1998. 31: 111-117.

9. Almusallam AA, Maslebuddin M, Abdul-Waris M, Khan MM, Effect of mix proportions on plastic shrinkage cracking of concrete in hot environments. Construction and Building Materials, 1998. 12: 353-358.

10. Bjøntegaard Ø, Hammer TA, Sellevold EJ. On the measurement of free deformation of early age cement paste and concrete. Cement and Concrete Composites, 2004. 26(5): 427-435.

11. Boshoff WP, Combrinck R. Modelling the severity of plastic shrinkage cracking in concrete. Cement and Concrete Research, 2013. 48: 34-39.

12. Darquennes A, Khokhar MIA, Rozière E, Loukili A, Grondin F, Staquet S. Early age deformations of concrete with high content of mineral additions. Construction and Building Materials, 2011. 25(4): 1836-1847.

13. Zhong MQ, Yang $\mathrm{CH}$, Wang $\mathrm{C}$. Influences of Fineness and Components of Cement on the Properties of Concrete and Countermeasures for Bridge Engineering, 2012, Department of Transport: Chongqing. in Chinese. 61 pages.

14. Aictin PC. Cements of yesterday and today concrete tomorrow. Cement and Concrete Composites, 2000. 30: 1349-1359.

15. Mehta PK, Monteiro PJM. Concrete: Microstructure, Properties, and Materials. $3^{\text {rd }}$ ed. 2005 : McGraw-Hill Professional.

16. Schneider M, Romer M, Tschudin M, Bolio H. Sustainable cement production-present and future. Cement and Concrete Research, 2011. 41(7): 642-650.

17. Bissonnette B, Pierre P, Pigeon M. Influence of key parameters on drying shrinkage of cementitious materials. Cement and Concrete Research, 1999. 29: 1655-1662.

18. Dao VTN, Dux PF, Morris PH. Crack propagation in concrete at very early ages. Magazine of Concrete Research, 2014. 66(13): 643-651.

19. Brooks JJ, Influence of mix proportions, plasticizers and superplasticizers on creep and drying shrinkage of concrete. Magazine of Concrete Research, 1989. 41: 145-153.

20. Mora-Ruacho J, Gettu R, Aguado A. Influence of shrinkage-reducing admixtures on the reduction of plastic shrinkage cracking in concrete. Cement and Concrete Research, 2009. 39(3): 141-146.

21. Kwak HG, Ha SJ, Plastic shrinkage cracking in concrete slabs, Part-1 A numerical model. Magazine of Concrete Research, 2006. 58: 505-516.

22. Kovler K, Lange DA, Stang H. Early age concrete-properties and performance. Cement and Concrete Composites, 2004. 26(5): 413-415.

23. Holt E. Contribution of mixture design to chemical and autogenous shrinkage of concrete at early ages. Cement and Concrete Research, 2005. 35(3): 464-472.

24. GB/T50080, Standard for test method of performance on ordinary fresh concrete, 2002, Standardization Administration of the People's Republic of China. 58 pages. 
25. GB/T-50082, Standard for test methods of long-term performance and durability of ordinary concrete, 2009, Standardization Administration of the People's Republic of China. 51 pages.

26. ASTM:C1579, Standard test method for evaluating plastic shrinkage cracking of retrained fiber reinforced concrete (Using a steel form insert), 2013, ASTM. 7 pages.

27. Taylor HF. Cement chemistry. 1997: Thomas Telford.

28. Neville AM. Properties of concrete. $4^{\text {th }}$ ed. 1995: Pearson.

29. Hamami AA, Turcry P, Ai-Mokhtar A. Influence of mix proportions on microstructure and gas permeability of cement pastes and mortars. Cement and Concrete Research, 2012. 42: 490-498.

30. Dellinghausen LM, Gastaldini ALG, Vanzin FJ, Veiga KK. Total shrinkage, oxygen permeability, and chloride ion penetration in concrete made with white Portland cement and blast-furnace slag. Construction and Building Materials, 2012. 37: 652-659.

31. Wittmann FH. On the action of capillary pressure. Cement and Concrete Research, 1976. 16: 4956.

32. Mindess S, Young JF, Darwin D. Concrete. 2003: Prentice Hall.

33. Combrinck R, Boshoff WP. Typical plastic shrinkage cracking behaviour of concrete. Magazine of Concrete Research, 2013. 65(8): 486-493.

34. Han J, Wang K, Shi J, Wang Y. Influence of sodium aluminate on cement hydration and concrete properties. Construction and Building Materials, 2014. 64: 342-349.

35. Pippard AB. Elements of classical thermodynamics. 1966: Cambridge at the university press.

36. Aictin PC, Neville AM. High-Performance Concrete Demystified. Concrete International, 1993. 15: 21-26.

37. Slowik V, Hübner T, Schmidt M, Villmann B. Simulation of capillary shrinkage cracking in cement-like materials. Cement and Concrete Composites, 2009. 31(7): 461-469.

38. ACI-305R, Hot weather concreting, 1999, ACI. 20 pages.

39. Nixon PJ, Lane DS. Experience from testing of the alkali reactivity of European aggregates according to several concrete prism test methods, 2006, BRE. 73 pages

40. Krivenko P, Drochytka R, Gelevera A, Kavalerova E. Mechanism of preventing the alkaliaggregate reaction in alkali activated cement concretes. Cement and Concrete Composites, 2014. 45: 157-165. 


\section{List of tables and figures}

3 Table

4 Table 1 Summary of experimental variables

5 Table 2 Chemical composition of cement clinker used (\% by mass)

6 Table 3 Mix proportions and slump of concretes tested in this study

$7 \quad$ Figure

8 Figure 1 Summary of results of fineness and alkali content for cements commonly used across 9 southwest China

10 Figure 2 Illustration of the test set-up for determination of concrete plastic shrinkage

11 Figure 3 Illustration of the test set-up for determination of plastic cracking of concrete

12 Figure 4 Relationship of cement hydration and specific area of cement

13 Figure 5 Relationship of cement hydration and alkali content

14 Figure 6 Influence of cement fineness and alkali content on compressive strength of concrete

15 Figure 7 Effect of cement fineness and W/C on concrete plastic shrinkage

16 Figure 8 Relationship between water evaporation rate and cement specific area

17 Figure 9 Effect of alkali content and W/C on plastic shrinkage concrete

18 Figure 10 Relationship between water evaporation rate and alkali content

19 Figure 11 Effect of cement fineness on maximum cracking width and cracking area

20 Figure 12 Effect of alkali content on maximum cracking width and cracking area

21 Figure 13 Relationship between water evaporation rate and behaviours of plastic cracking

Figure 14 Summary of total plastic shrinkage and derived shrinkage for concrete with different size cements and alkali contents 
Table 1 Summary of experimental variables

\begin{tabular}{l|l|l|l}
\hline \multicolumn{5}{l}{ Factors and levels } & Alkali content & W/C \\
\hline Factor & Cement fineness & $\begin{array}{l}0.4,0.8,1.2 \% \text { by mass of } \\
\text { cement }\end{array}$ & $0.35,0.40$ \\
\hline Level & $275,337,385 \mathrm{~m}^{2} / \mathrm{kg}$ &
\end{tabular}

\section{Property determined}

\begin{tabular}{l|l}
\hline General property & Slump, Compressive strength at the age of 3,7 and 28 days \\
\hline Influencing property & Cement hydration, Water evaporation rate, Plastic shrinkage \\
\hline Response property & Maximum cracking width, Cracking area \\
\hline
\end{tabular}

Note: the value of $275,337,385 \mathrm{~m}^{2} / \mathrm{kg}$ refers to specific area of cement particles; the value of $0.4,0.8,1.2 \%$ refers to alkali content, calculated based on $\mathrm{Na}_{2} \mathrm{O}$ mass percent.

5

Table 2 Chemical composition of cement clinker used ( $\%$ by mass)

\begin{tabular}{cccccccccc}
\hline $\mathrm{CaO}$ & $\mathrm{SiO}_{2}$ & $\mathrm{Al}_{2} \mathrm{O}_{3}$ & $\mathrm{Fe}_{2} \mathrm{O}_{3}$ & $\mathrm{MgO}$ & $\mathrm{SO}_{3}$ & $\mathrm{Na}_{2} \mathrm{O}$ & $\mathrm{K}_{2} \mathrm{O}$ & f-CaO & Loss on ignition \\
\hline 63.60 & 20.20 & 5.89 & 3.92 & 1.46 & 1.37 & 0.18 & 0.34 & 1.46 & 1.58 \\
\hline
\end{tabular}

7 Note: $\mathrm{f}-\mathrm{CaO}$ represents the 'free' $\mathrm{CaO}$ in the clinker.

8

9

\begin{tabular}{|c|c|c|c|c|c|c|c|c|c|}
\hline Factor & $\begin{array}{l}\text { Cement } \\
\left(\mathrm{kg} / \mathrm{m}^{3}\right)\end{array}$ & $\begin{array}{c}\text { Sand } \\
\left(\mathrm{kg} / \mathrm{m}^{3}\right)\end{array}$ & $\begin{array}{c}\mathrm{CA} \\
\left(\mathrm{kg} / \mathrm{m}^{3}\right)\end{array}$ & $\begin{array}{l}\text { Water } \\
\left(\mathrm{kg} / \mathrm{m}^{3}\right)\end{array}$ & $\begin{array}{l}\text { SP } \\
(\%)\end{array}$ & $\begin{array}{l}\mathrm{W} / \mathrm{C} \\
(\%)\end{array}$ & $\begin{array}{r}\text { Cement } \\
\text { fineness } \\
\left(\mathrm{m}^{2} / \mathrm{kg}\right)\end{array}$ & $\begin{array}{c}\text { Alkali } \\
\text { content } \\
(\%)\end{array}$ & $\begin{array}{r}\text { Slump } \\
(\mathrm{mm})\end{array}$ \\
\hline \multirow{6}{*}{$\begin{array}{l}\text { Effect of } \\
\text { cement } \\
\text { fineness }\end{array}$} & 420 & 689 & 1123 & 168 & 0.60 & \multirow{3}{*}{0.40} & 275 & \multirow{3}{*}{0.4} & 170 \\
\hline & 420 & 689 & 1123 & 168 & 0.65 & & 337 & & 155 \\
\hline & 420 & 689 & 1123 & 168 & 0.70 & & 385 & & 160 \\
\hline & 420 & 697 & 1136 & 147 & 0.90 & \multirow{3}{*}{0.35} & 275 & \multirow{3}{*}{0.4} & 150 \\
\hline & 420 & 697 & 1136 & 147 & 1.00 & & 337 & & 160 \\
\hline & 420 & 697 & 1136 & 147 & 1.10 & & 385 & & 150 \\
\hline \multirow{6}{*}{$\begin{array}{l}\text { Effect of } \\
\text { alkali } \\
\text { content }\end{array}$} & 420 & 689 & 1123 & 168 & \multirow{3}{*}{0.65} & \multirow{3}{*}{0.40} & \multirow{3}{*}{275} & 0.4 & 167 \\
\hline & 420 & 689 & 1123 & 168 & & & & 0.8 & 155 \\
\hline & 420 & 689 & 1123 & 168 & & & & 1.2 & 130 \\
\hline & 420 & 697 & 1136 & 147 & \multirow{3}{*}{1.00} & \multirow{3}{*}{0.35} & \multirow{3}{*}{275} & 0.4 & 155 \\
\hline & 420 & 697 & 1136 & 147 & & & & 0.8 & 130 \\
\hline & 420 & 697 & 1136 & 147 & & & & 1.2 & 98 \\
\hline
\end{tabular}

Table 3 Mix proportions and slump of concretes tested in this study

Note: CA represents coarse aggregate contents; SP refers to superplasticiser dosage as a percentage by mass of the total binder content. 


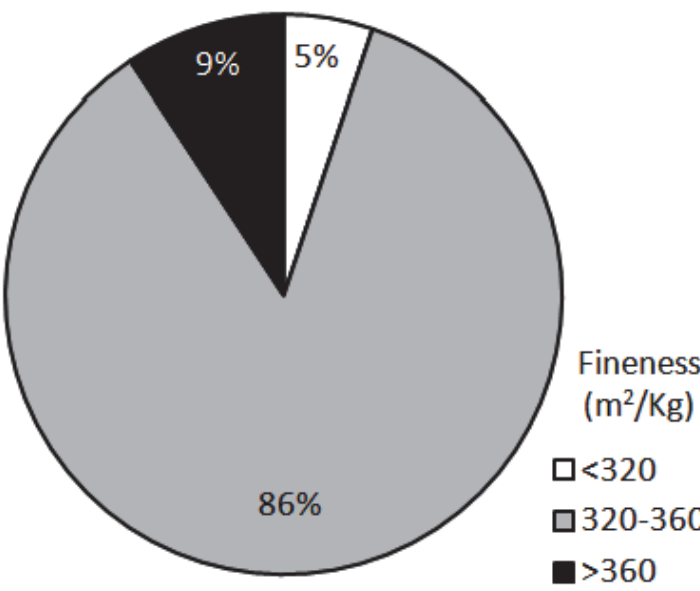

(a) Cement fineness

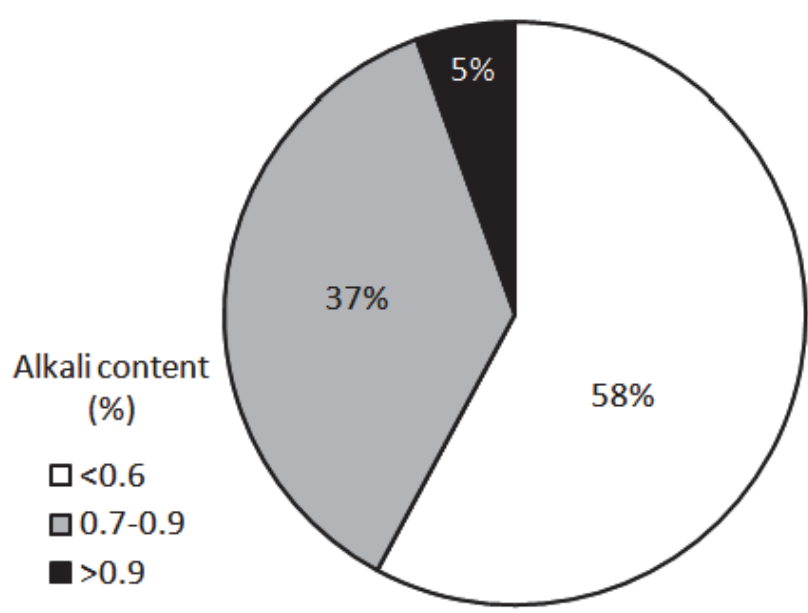

(b) Alkali content

Figure 1 Summary of results of fineness and alkali content for cements commonly used across southwest China

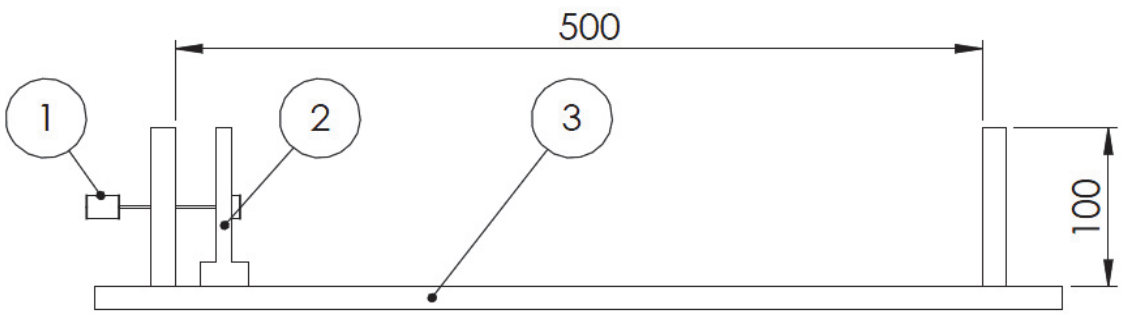

Note:

1 represents the part connecting with laser sensor

2 represents the part embedded in concrete

3 represents the mould unit: $\mathrm{mm}$

(a) Mould for plastic shrinkage measurement

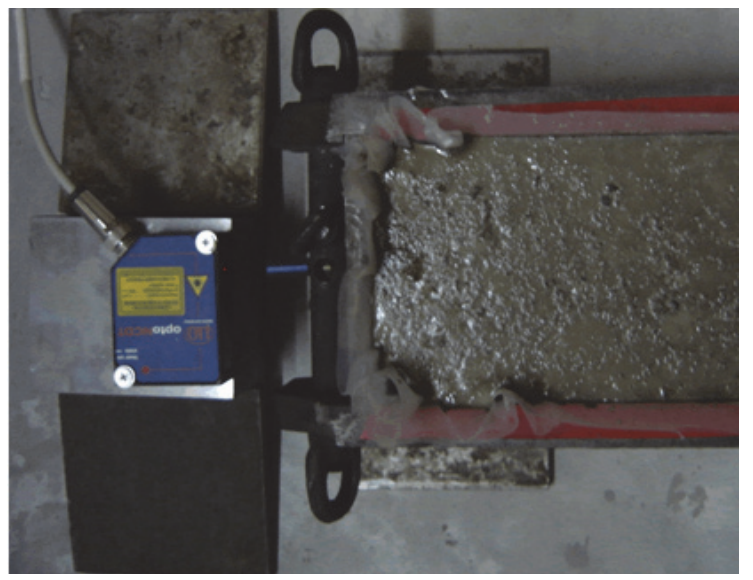

(b) Test set-up for shrinkage measurement

Figure 2 Illustration of the test set-up for determination of concrete plastic shrinkage 


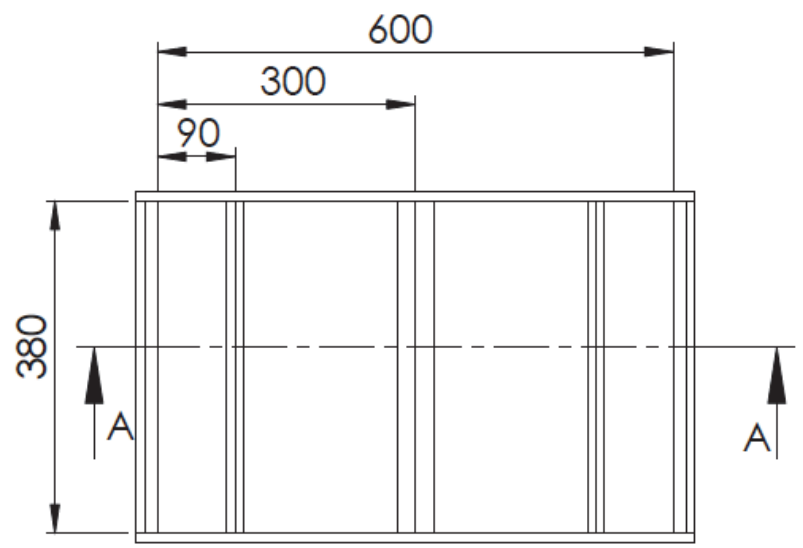

Plan view

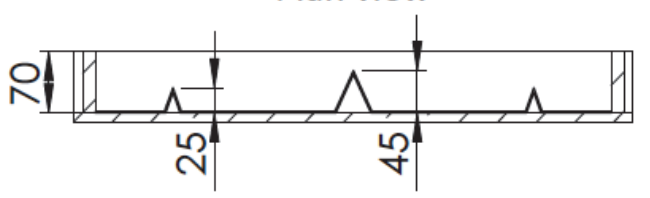

Section view: A-A

Unit: $\mathrm{mm}$.

(a) Mould for plastic cracking test

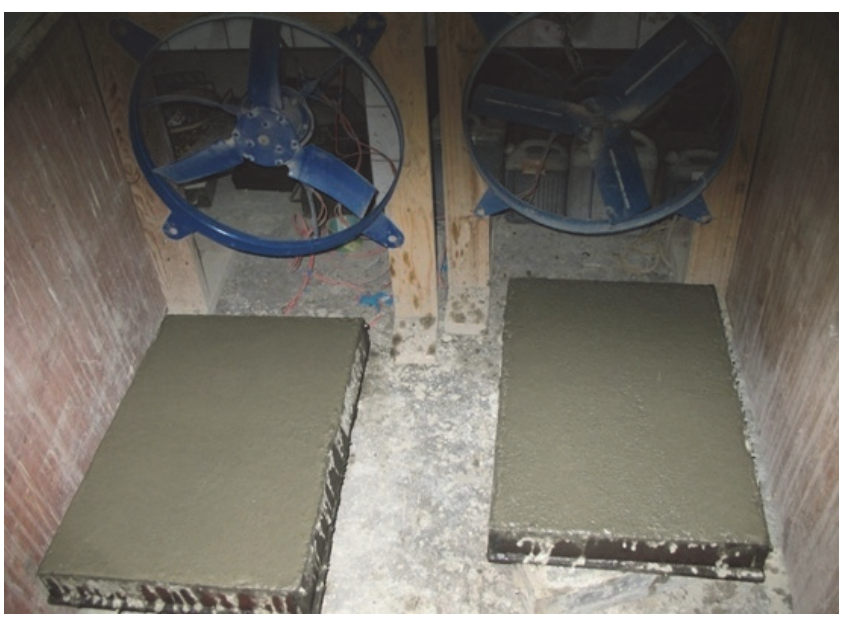

(b) Test set-up for plastic cracking measurement

Figure 3 Illustration of the test set-up for determination of plastic cracking of concrete 


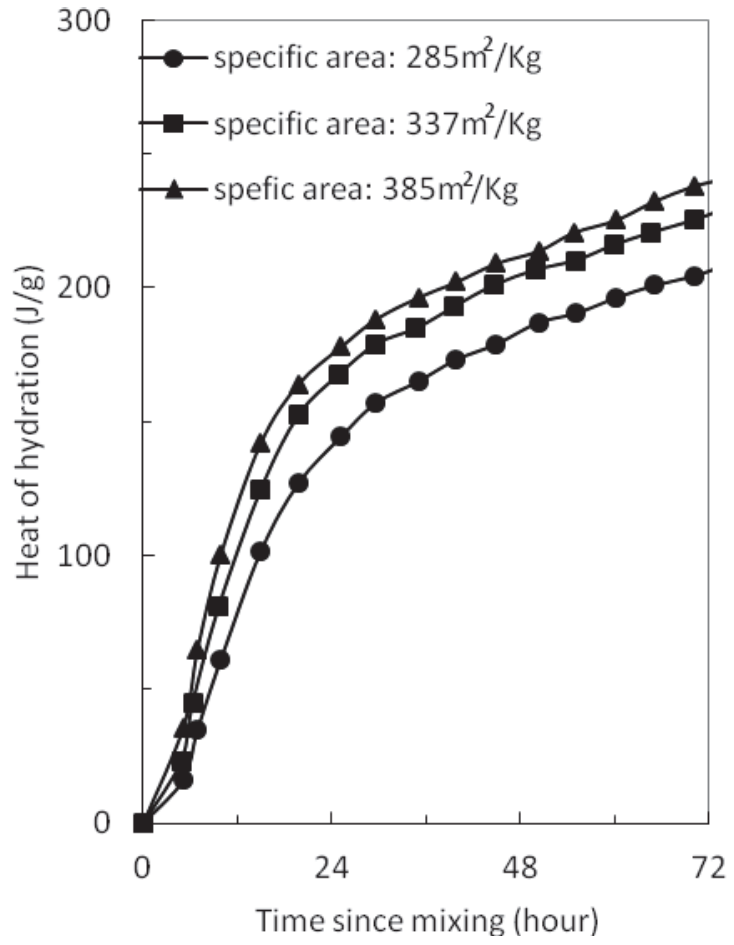

(a) Relation between fineness and heat of cement hydration

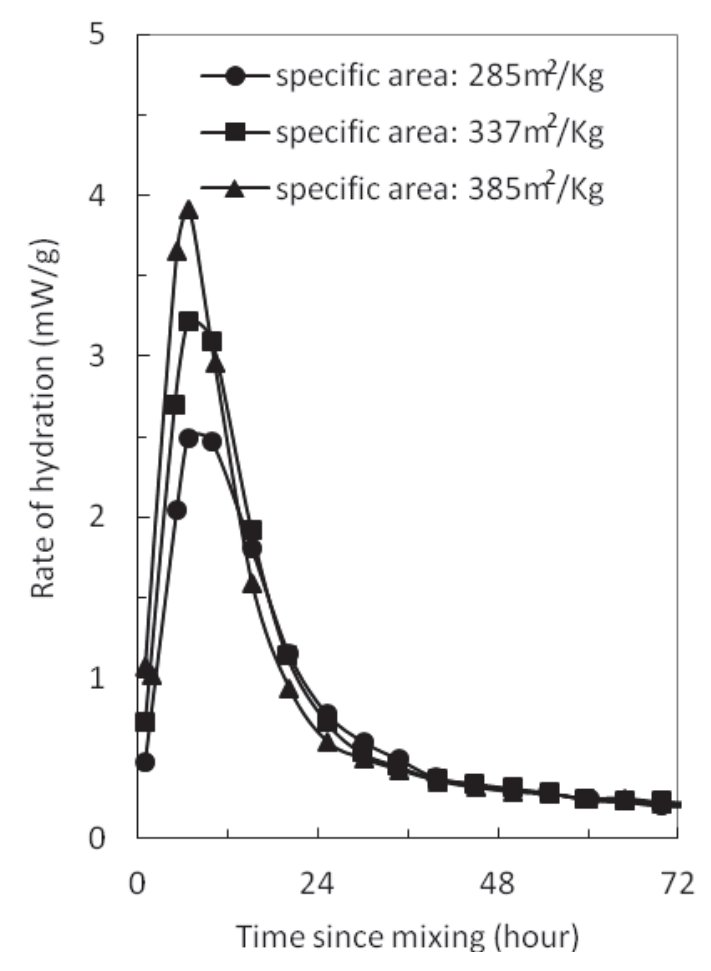

(b) Relation between fineness and rate of cement hydration

Figure 4 Relationship of cement hydration and specific area of cement

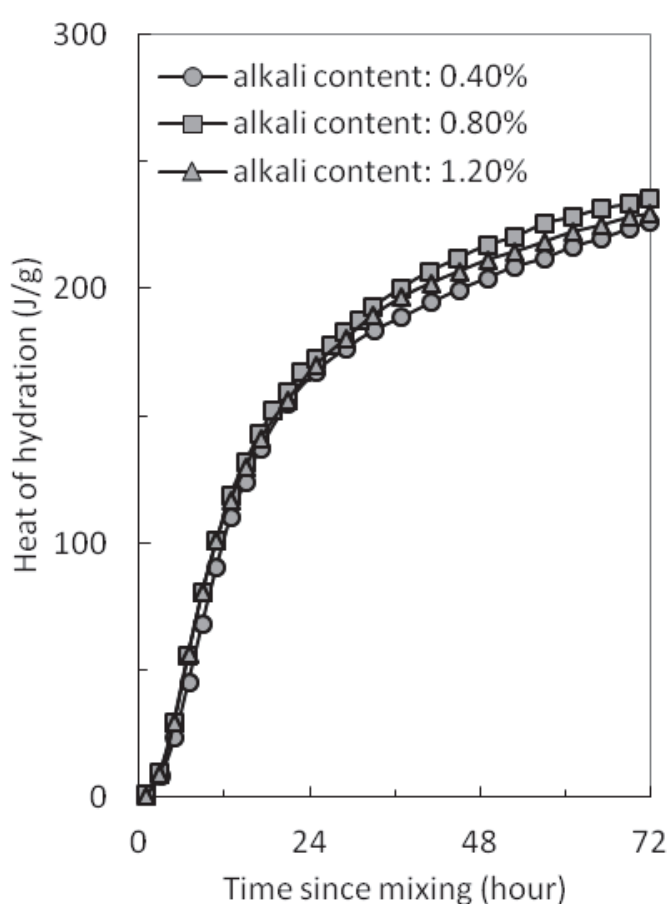

(a) Relation between alkali content and heat of cement hydration

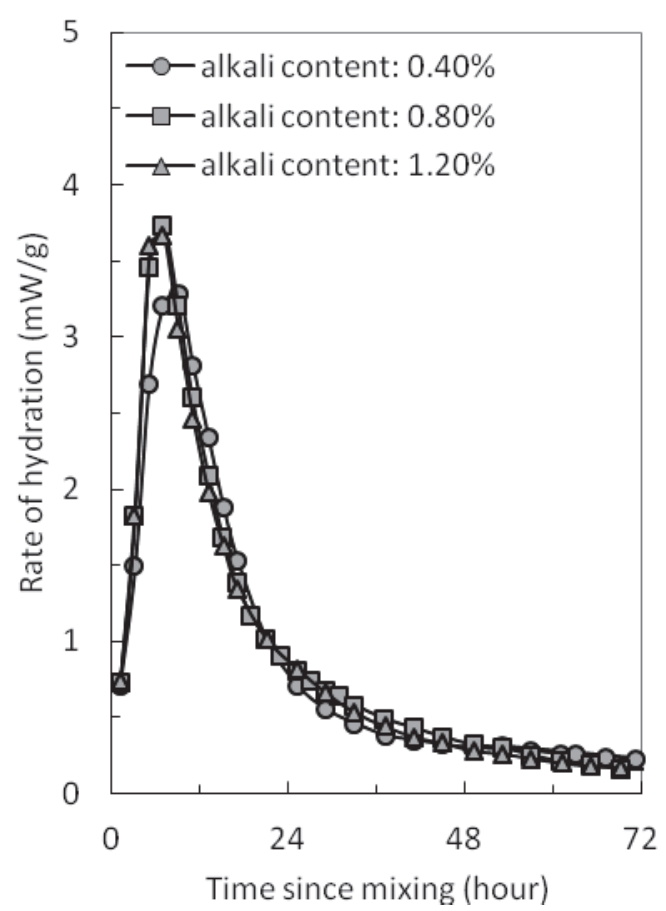

(b) Relation between alkali content and of cement hydration rate

Figure 5 Relationship of cement hydration and alkali content (The specific area of cement is $275 \mathrm{~m}^{2} / \mathrm{kg}$ ) 


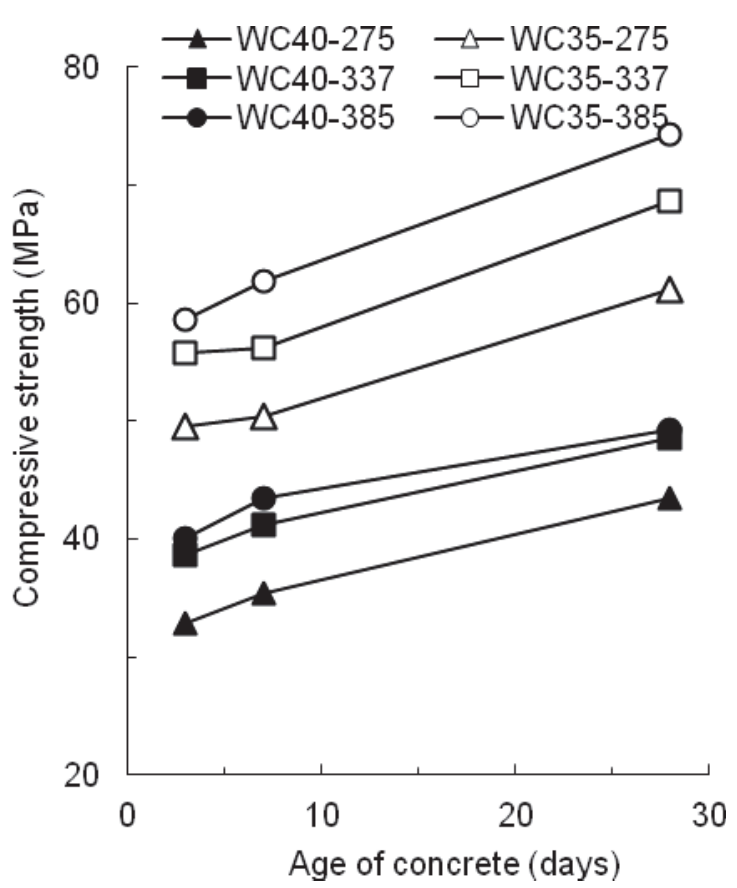

(a) Influence of cement fineness on compressive strength of concrete

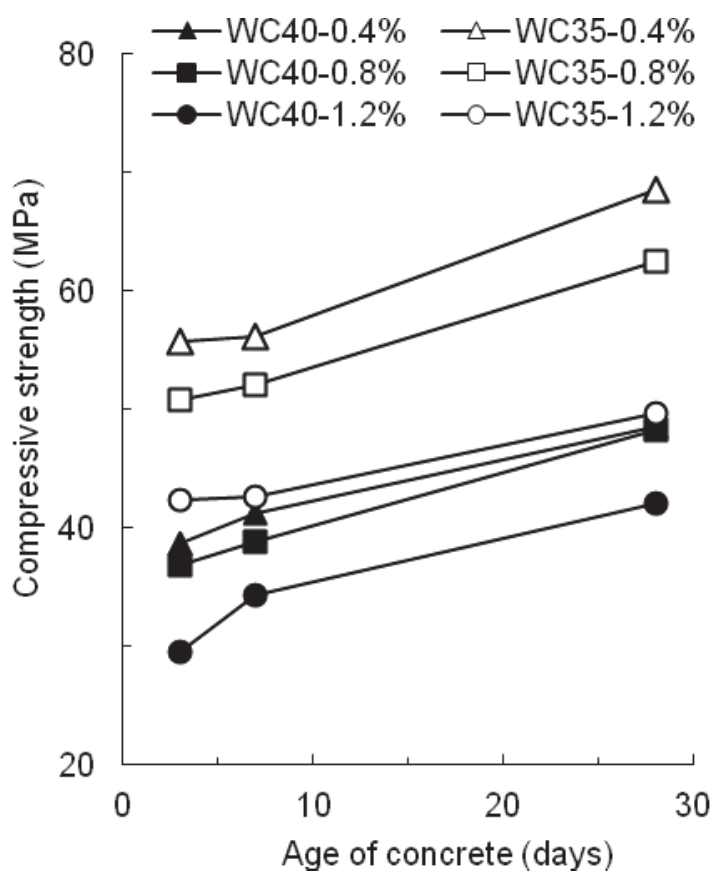

(b) Influence of alkali content on compressive of concrete

Figure 6 Influence of cement fineness and alkali content on compressive strength of concrete

(WC40, WC35 refers to the W/C ratio; 285, 337, 385 refers to the specific area, $\mathrm{m}^{2} / \mathrm{kg} ; 0.40 \%, 0.8 \%$, $1.2 \%$ refers to alkali content.)

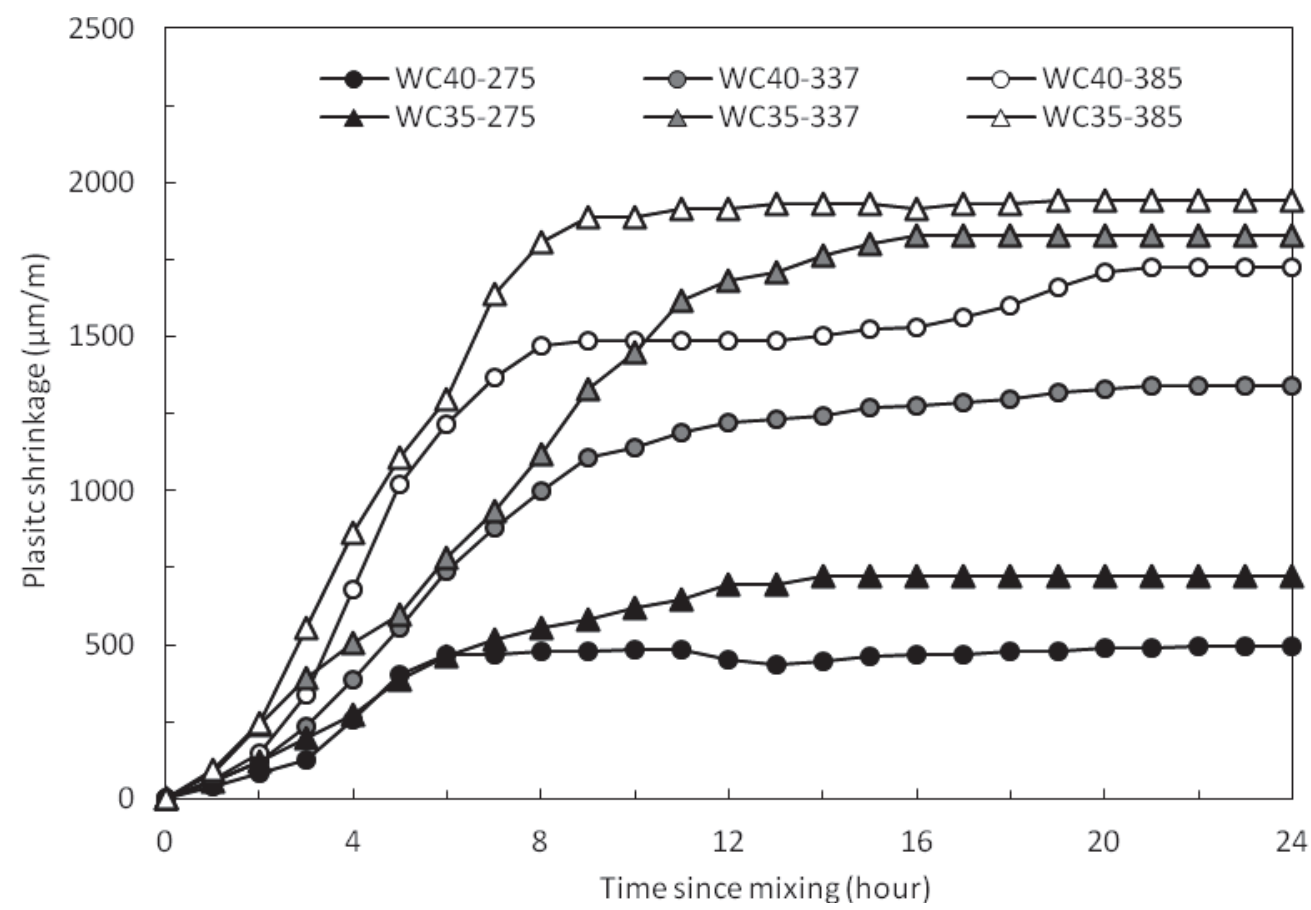

Figure 7 Effect of cement fineness and $\mathrm{W} / \mathrm{C}$ on concrete plastic shrinkage

(WC40, WC35 refers to the $\mathrm{W} / \mathrm{C}$ ratio; 285, 337, 385 refers to the specific area, $\mathrm{m}^{2} / \mathrm{kg}$ and alkali content is $0.4 \%$.) 


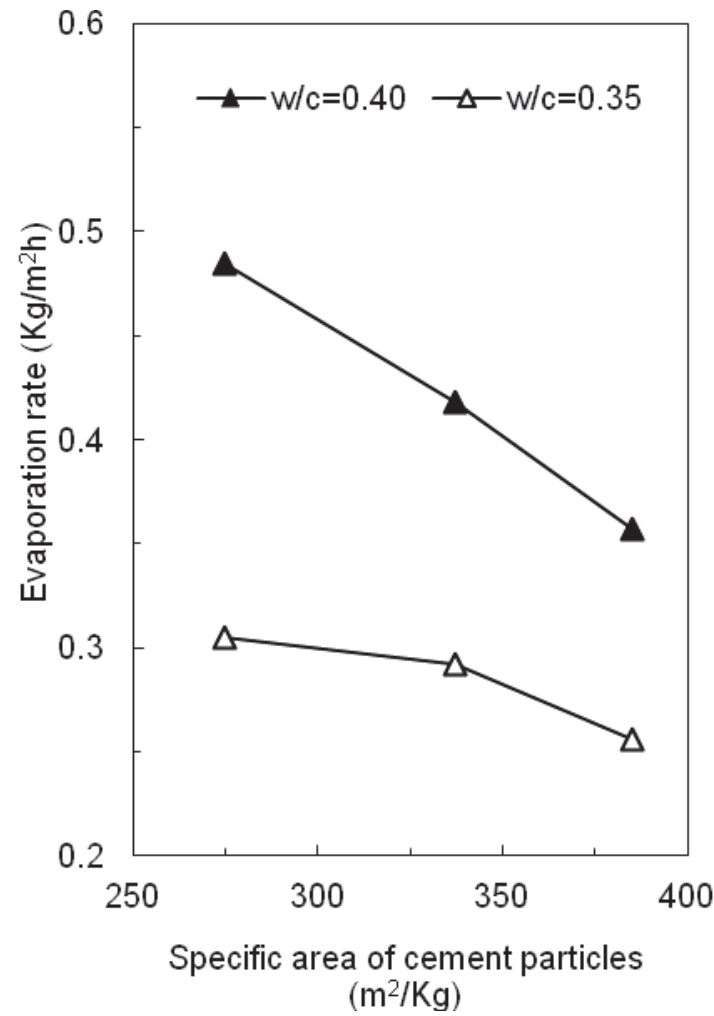

Figure 8 Relationship between water evaporation rate and cement specific area

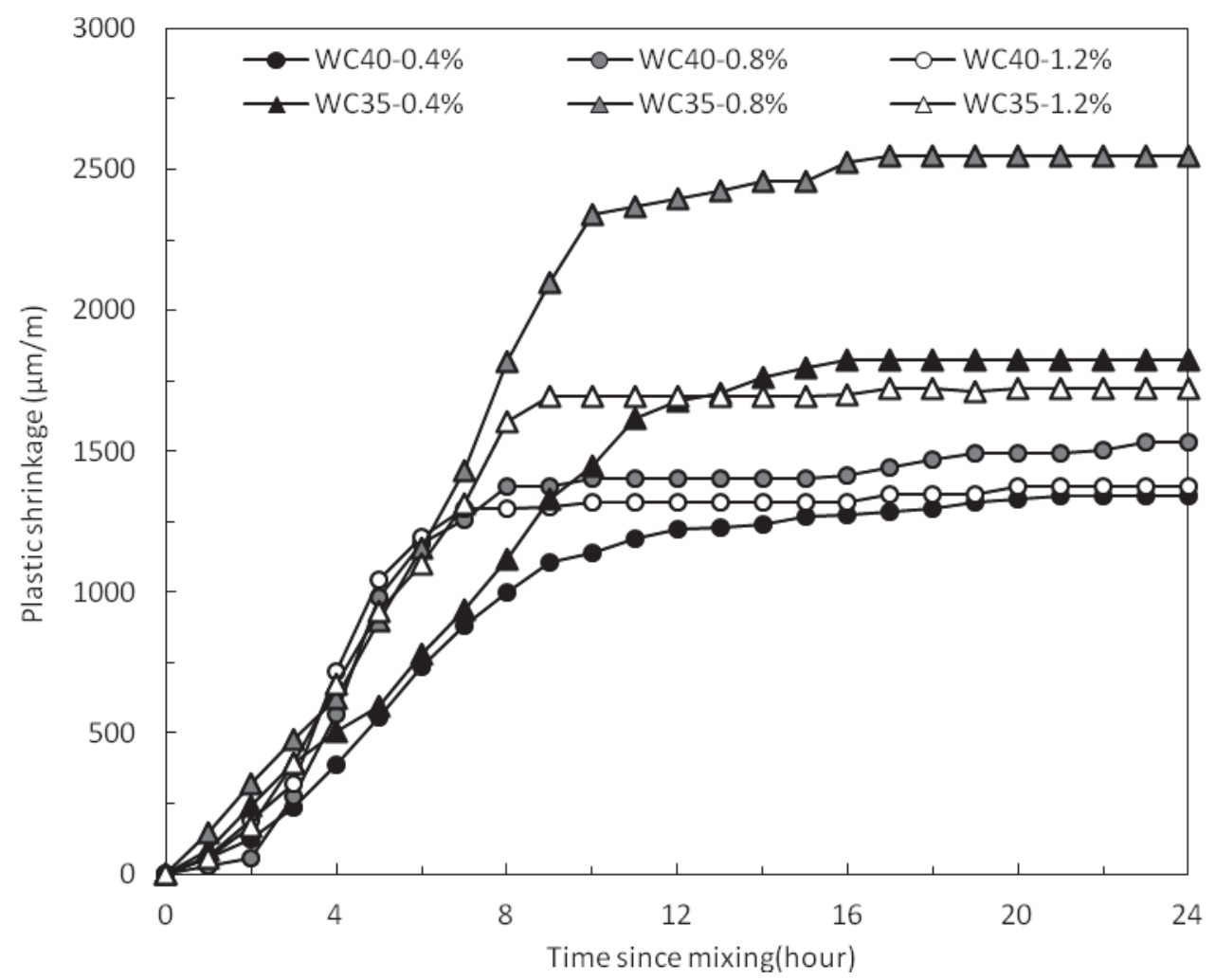

Figure 9 Effect of alkali content and $\mathrm{W} / \mathrm{C}$ on plastic shrinkage concrete

(WC40, WC35 refers to the $\mathrm{W} / \mathrm{C}$ ratio; $0.40 \%, 0.8 \%, 1.2 \%$ refers to alkali content and the specific area of cement is $285 \mathrm{~m}^{2} / \mathrm{kg}$.) 


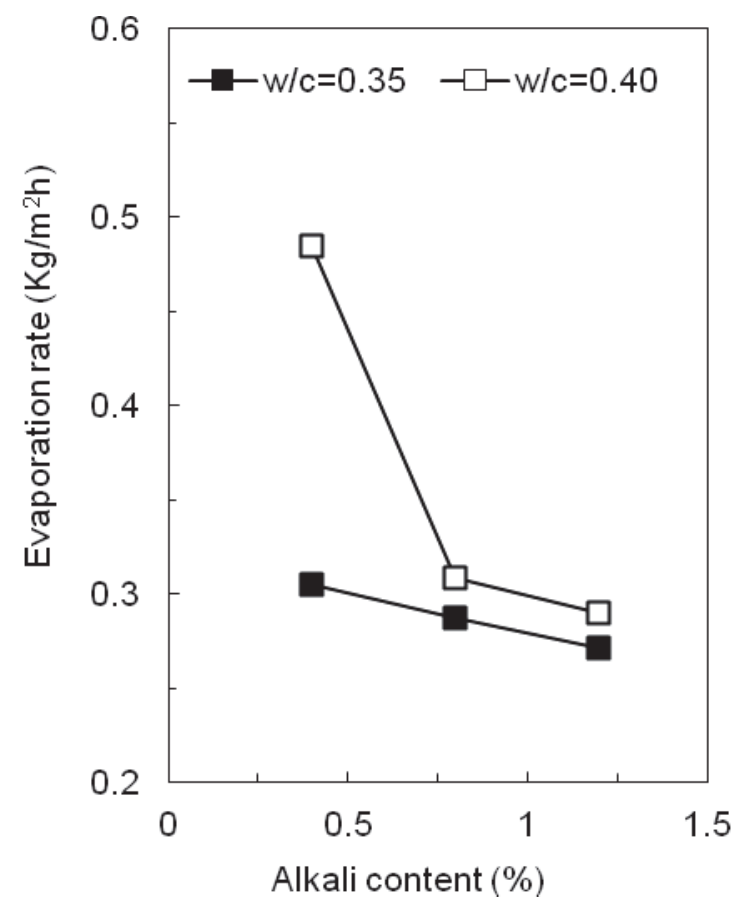

Figure 10 Relationship between water evaporation rate and alkali content
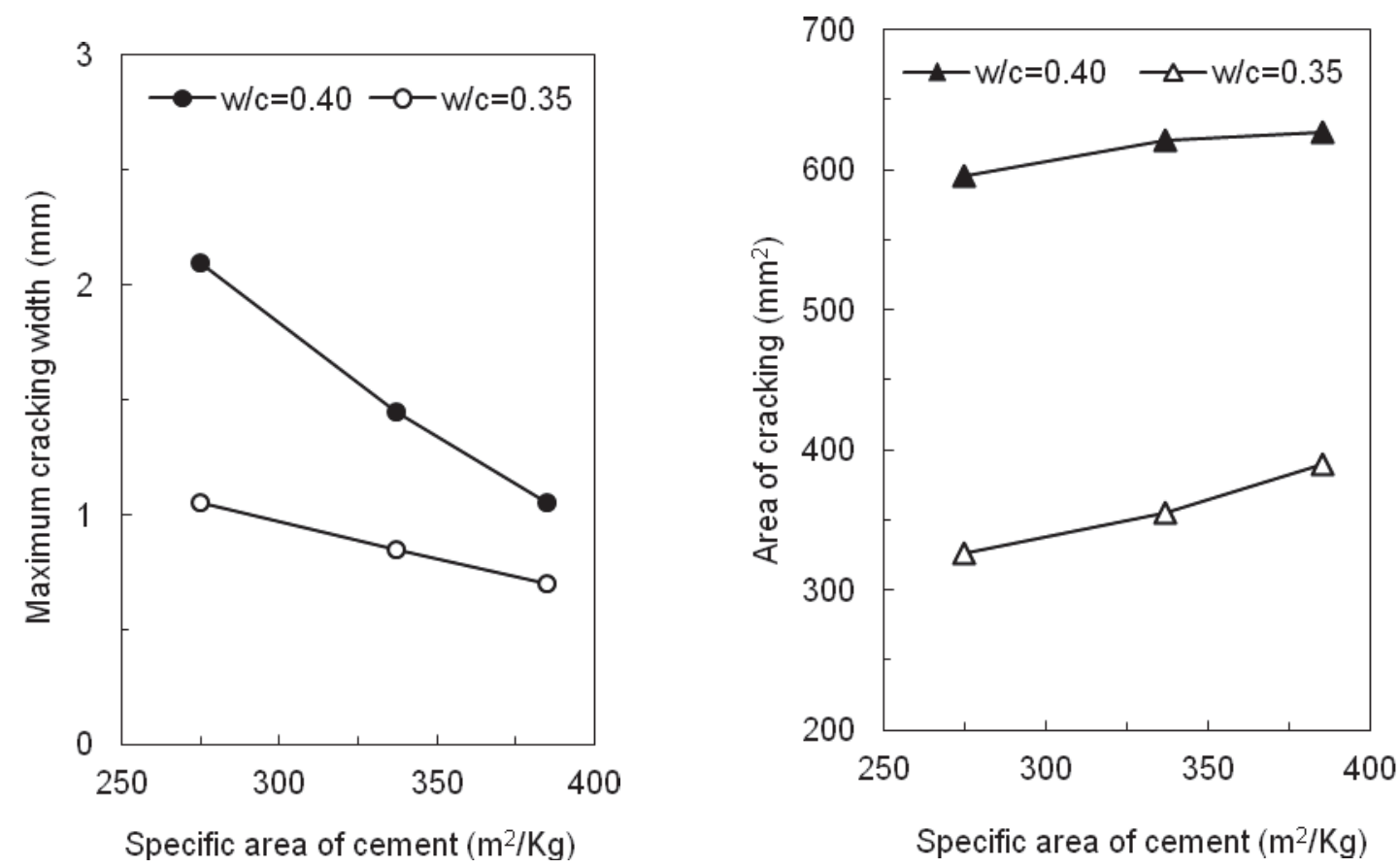

(a) Effects of fineness and $\mathrm{W} / \mathrm{C}$ on the maximum cracking width

(b) Effects fineness and W/C on the area of cracking

Figure 11 Effect of cement fineness on maximum cracking width and cracking area 


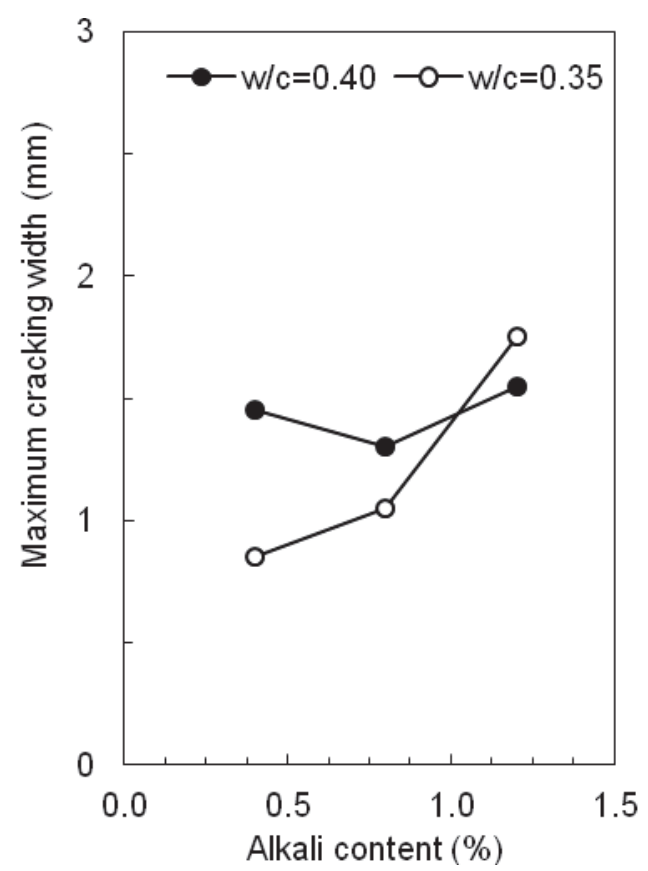

(a) Effects of alkali content and W/C on the maximum cracking width

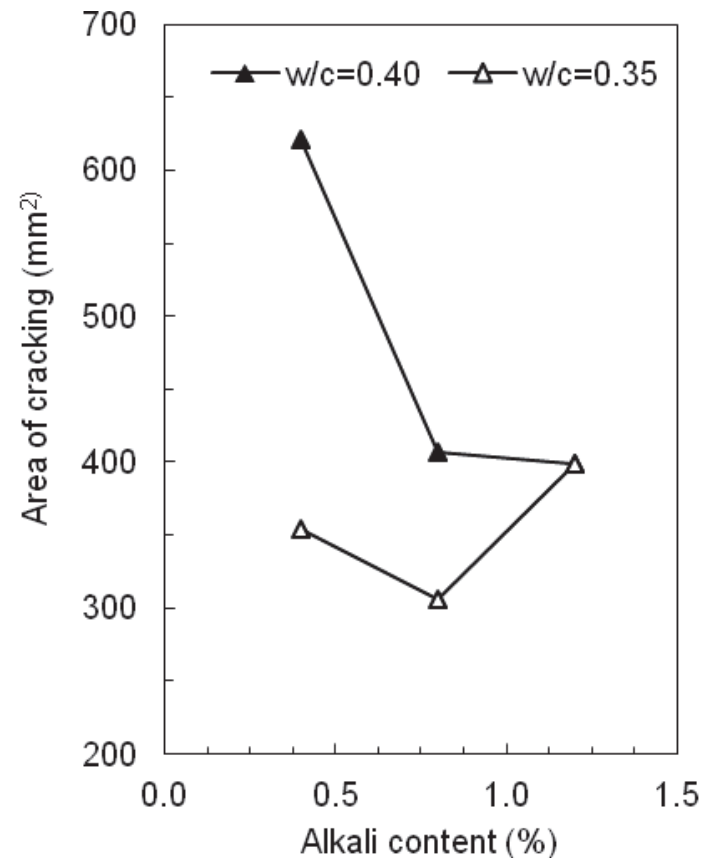

(b) Effects alkali content and W/C on the area of cracking

Figure 12 Effect of alkali content on maximum cracking width and cracking area for concretes with different $\mathrm{W} / \mathrm{C}$ ratios

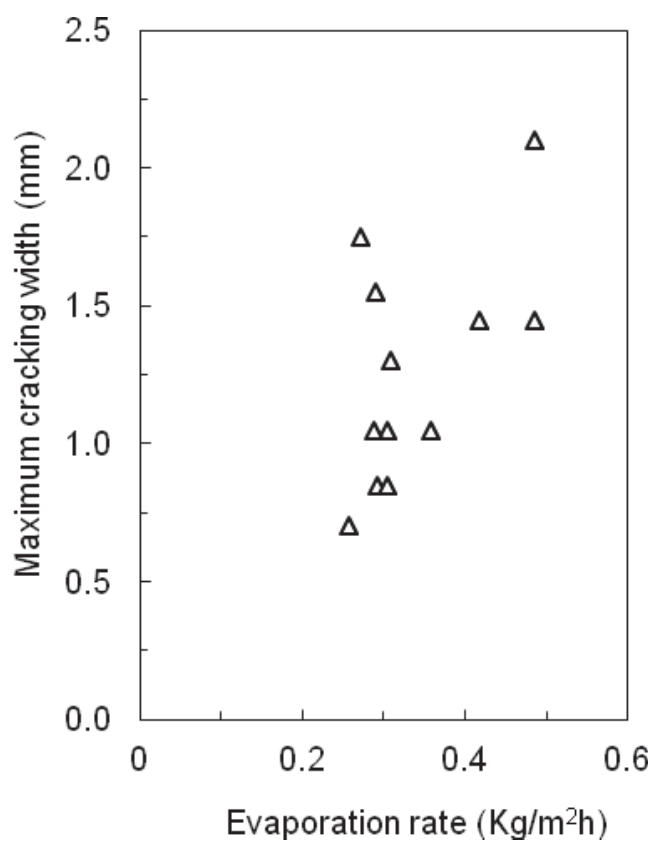

(a) Relationship between maximum cracking width and evaporation rate

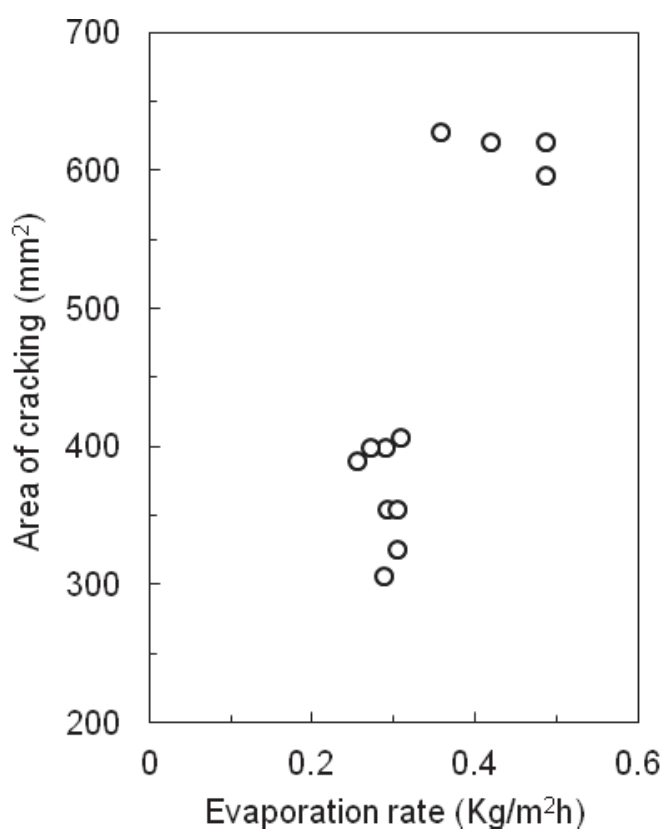

(b) Relationship between cracking area of cracking and evaporation rate

Figure 13 Relationship between water evaporation rate and behaviours of plastic cracking (maximum cracking width and cracking area) 


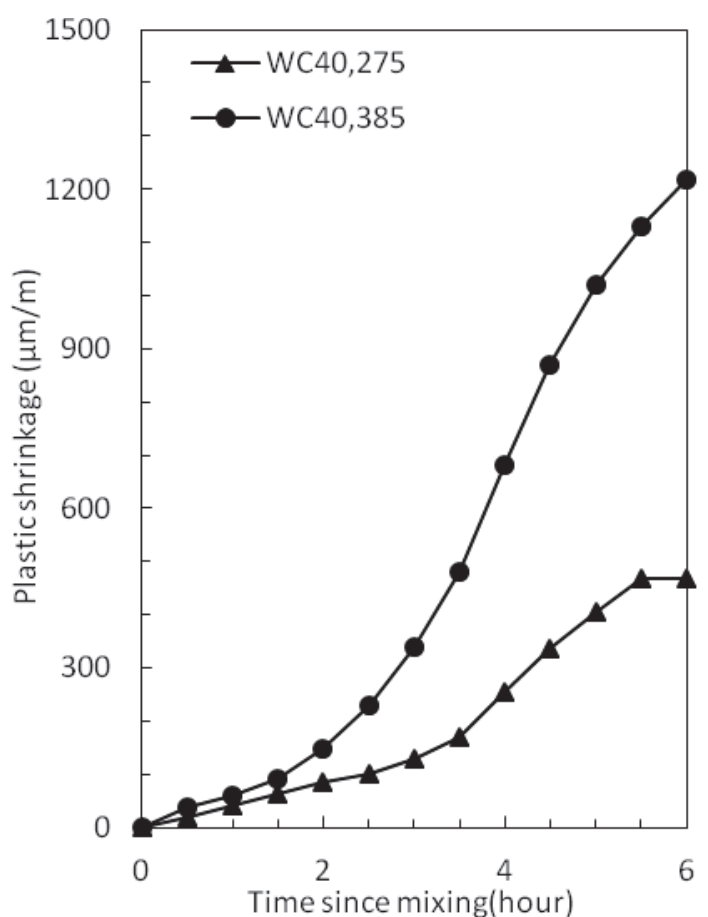

(a) 6 hour plastic shrinkage of concrete with different size cements

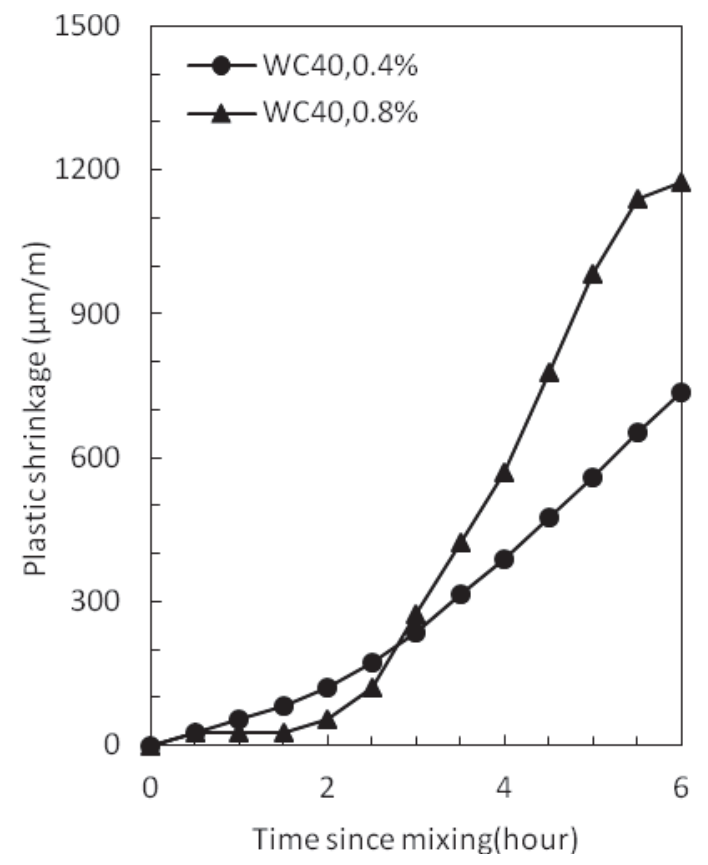

(c) 6 hour plastic shrinkage of concrete with alkali contents

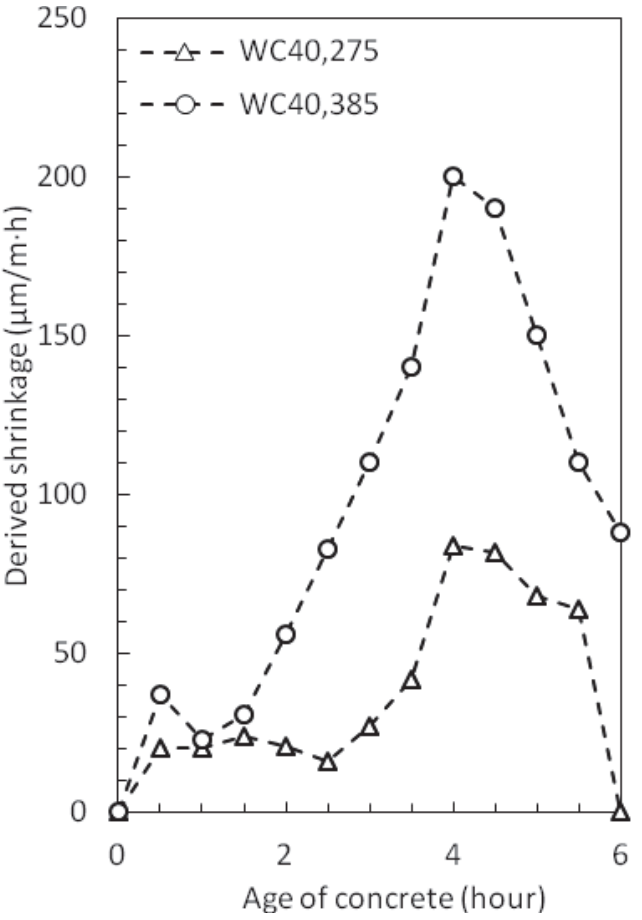

(b) Derived shrinkage of concrete with different size cements

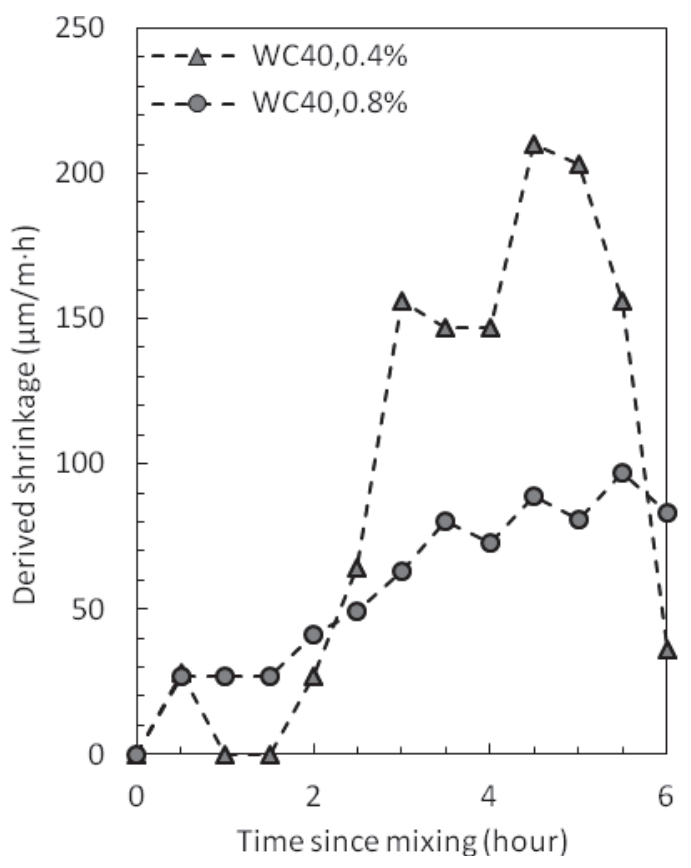

(d) Derived shrinkage of concrete with alkali contents

Figure 14 Summary of total plastic shrinkage and derived shrinkage for concrete with different size cements and alkali contents 